\title{
Using social network analysis techniques to study the efficiency of interproject communication
}

\author{
Dmitry Plokhov ${ }^{1,2}$, llya V. Osipov ${ }^{1, a}$ and Gregory Bubnov ${ }^{1,2}$ \\ ${ }^{1}$ Moscow Technological Institute, 119334 Moscow, Russia \\ ${ }^{2}$ Moscow Institute of Physics and Technology, 141700 Dolgoprudny Moscow reg., Russia
}

\begin{abstract}
Traditional performance monitoring techniques in project management are based on classical measures costs, schedule and scope of work. But focusing our view on these indices and their derivatives we can overlook one of the most important elements of project management - project participants. Degrees of their coordination, cohesion and collaboration directly influence on the extent to which project goals could be achieved. Communications and relations between participants play a vital role of special glue holding project parts together. Besides, communication environment integrate within itself information about all aspects of a project - successes, failures and conflicts. Character of interpersonal relations and structure of communications between participants are proposed as indicators of successfulness or failures. In present report project participants are considered as a social network. Using social network analysis (SNA) techniques provides opportunities to examine links between structural characteristics of interproject communication networks and project performance.
\end{abstract}

\section{Introduction}

A project can be viewed as a temporal organization formed within an enterprise for achieving unique goals [1]. In addition to create a unique product, service or result, particular characters of projects are dynamic environment in which a project is managed and high level of uncertainty. Of course, processes optimization and agile management techniques are of high importance for the project success. However, as were rightly pointed out in the article of T. Cooke-Davies [2], project results are delivered by people, not by processes and systems. Interacting each other and the environment, project participants should constantly adopt their work to new conditions and challenges tactics to eventually achieve the major strategic goal - to meet customer needs. Communications and relation between people determine the quality of the processes, and therefore the quality of project management in general [3].

The most common approach for evaluating project management performance is based on comparison of actual project measures with approved constraints on costs, time and specification of work. This approach, that can be rightly called classical, makes possible to get birdeye view on the situation through a set of formal metrics. Although an analysis by classical metrics and their derivatives is clear and well-formalized, it seems extremely difficult to use such metrics to evaluate impact of major social factors - communications and social relations that that move the project team from efficient to effective [4].
A communication environment acts not only as a data transfer system or a messenger, but it also integrates not only for messaging, but it also integrates all information in broad terms about the project. Project initiation proceeds in parallel with forming of a social ties network, the members of which are the project participants. The communication structure is inevitably interwoven with informal relations that also have great impact on the work environment and complement relations based on functional and hierarchical links [5]. Problems or failures during the work, as well as their overcoming and successes affect participants and how they interact with each other. Thus, on the one hand, participants' places in the network are determined by their formal (functional and hierarchical) positions, on the other hand, by such imprescriptible factors as social prestige, readiness to cooperate, sympathy or antipathy towards others.

The social nature of project management is also reflected in a link between emerging mismatches or contradictions and conflicts between participants. There are two opposing points of view on the role of conflict. Traditional views supporters consider conflicts as a threat to a project and its environment. So conflicts should be avoided. Given the modern behavioral framework in management, conflicts are inevitable parts of the human organization, and with proper approach they can bring benefits and give right clues to resolve contradictions [6]. The study [7] conducted was focused on identifying the main causes of conflict in projects and covered almost all aspects of project management. The general consensus of

\footnotetext{
${ }^{a}$ Corresponding author: ilya@osipov.ru
} 
proponents of traditional and behavioral viewpoints is that conflicts can be symptoms of problems in project management and, not being solved, potentially lead to damages [8]. In the current research, we aim to investigate a communication structures and their character in projects that were in a conflict state. During the study of three projects, information about communication between the main participants were collected and considered. An analysis of a links between communications structures and the project's success rate is fulfilled.

\section{Social network analysis techniques for studying interproject communication}

Techniques of social network analysis (SNA) are used extensively for studying of relations within organizations and between them. The main part of such research is based on analysis of corporate communications and information from the participants obtained through surveys and interviews. In relation to the project management, researches interests are targeted on features of interaction within virtual teams and the evaluation of their performance $[9,10]$, the issues of building effective communication between organization / project members [11], optimal conditions for spreading of practices and knowledge [12].

Communication issues were the central topics of the significant number of researches in the context of studying project management practices in construction and engineering industries. In [13-16] the authors considered the possibility of applying the social networks concept and analysis techniques to improve the efficiency of construction projects. The analysis of the links between the structure of teams' communications and innovative projects effectiveness was undertaken by S. A. Titov [18].

The growth of interest in SNA methods results from their flexibility that allows possibility to explore the communities and organizations of all sizes, to identify and visualize the formal and informal networks, to evaluate the quantitative parameters of communication structures and conduct a comparative analysis on their basis. In addition, several powerful software products, including free, were developed for supporting researchers to use SNA methods. These user-friendly products allow building and analyzing networks of various sizes. All this makes the use of social network analysis methods is very promising for the studies of organization and project communication networks.

\subsection{Research methods}

Earlier it was noted that communication structures and their character are the essential success factors on projects. From the full variety of project communication issues this study considered links between the structural balance of the project network and the project success rate by the end of the conflict. According to the theory of F. Heider [19], there is structural balance in a social network when in do not contain relations - "positive attitudes (friendship, cooperation) between A and B and between $\mathrm{B}$ and $\mathrm{C}$, but negative attitudes (hostility, rivalry) between $\mathrm{B}$ and $\mathrm{C}$ ". It is supposed that balanced networks are more comfortable for participants and more stable than unbalanced. Thus, the conflict should split a network into balanced sub-groups (conflict parties) consisting of like-minded people who share similar points of view.

The studied project networks were built information by using data about communications between the participants by formal and informal ways, directly related to the certain project. Also intensity (evaluated in the form of a numeric attribute) and character (attitude) of communications are taken into account.

The authors distinguished three levels of communication intensity: low, medium and high, which were associated with the values 0,1 and 2 respectively. Consideration was given to mutual directed communication, i.e. the intensity of the evaluated communications between the certain participants pair was the same from the point of view of each of them.

Character (attitude) of communication communications associated with the "+" sign, if the communications were friendly, i.e. participants had mutual sympathy or common ground, or "-"sign in case of antipathy or difference in views. In each of the projects previously mentioned regarding the subject matter of the conflict. The positions conditionally designated as "Agree", "Disagree" or "Neutral".

The basis for the study was the information about the following three projects:

- The project $A$. 14 participants. The main object: development of the online educational games [19]. The conflict subject: disagreements about the final versions of the game concept and scenarios. Summary of the conflict: disagreements were finally overcome by harmonizing the wishes of all parties, but time was substantially out of schedule. Overall assessment of project results given by the participants is positive.

- The project B. 9 participants. The main object: development of an enterprise information system. The conflict subject: different views on technical solutions and disagreements about quality assessment of project results. Summary of the conflict: the parties were not able to reach a consensus which led fail to meet the project deadlines, and, subsequently, the project was cancelled.

- The project $C$. 7 participants. The main object: developing of educational online service [20]. The conflict subject: reforming of the project organization structure, attracting new members. Summary of the conflict: the deadlines were broken; some of the participants were out of the project. A key problem raised by participants was an impossibility of compromise on the conflict issue.

Summary data about communications (intensity and character) are presented in tables 1-3. These tables indicate the participants' position on the matter of the conflicts (A - "Agree"; D - "Disagree"; N - "Neutral").

It should be noted that the projects have been implemented in different organizations and by different teams, even though planned times of project duration had roughly the same. 
Table 1. The matrix of communications in the project A.

\begin{tabular}{|c|c|c|c|c|c|c|c|c|c|c|c|c|c|c|}
\hline Participant & A1 & A2 & A3 & A4 & A5 & A6 & A7 & A8 & A9 & A10 & A11 & A12 & A13 & A14 \\
\hline $\mathbf{A 1}$ & & 2 & -1 & & & & & & & & & 1 & & 1 \\
\hline A2 & & & 1 & 1 & & & & & & & & 2 & 1 & 1 \\
\hline $\mathbf{A 3}$ & & & & 2 & 1 & 2 & & -1 & & & & 1 & & \\
\hline A4 & & & & & & 1 & & 1 & & 1 & & 2 & & \\
\hline A5 & & & & & & & 1 & 2 & 1 & & & & & \\
\hline A6 & & & & & & & 2 & 2 & 1 & 1 & 1 & 1 & 2 & \\
\hline A7 & & & & & & & & 2 & 1 & 2 & 1 & & & \\
\hline A8 & & & & & & & & 2 & 1 & 2 & & & \\
\hline A9 & & & & & & & & & & & 1 & & & \\
\hline A10 & & & & & & & & & & 1 & & & \\
\hline A11 & & & & & & & & & & & & & & \\
\hline A12 & & & & & & & & & & & & & 2 & 2 \\
\hline A13 & & & & & & & & & & & & & 2 \\
\hline A14 & & & & & & & & & & & & & & \\
\hline Position & D & N & D & D & A & N & A & A & N & A & N & N & N & N \\
\hline
\end{tabular}

Table 2. The matrix of communications in the project B.

\begin{tabular}{|c|c|c|c|c|c|c|c|c|c|}
\hline Participant & B1 & B2 & B3 & B4 & B5 & B6 & B7 & B8 & B9 \\
\hline B1 & & 1 & 1 & & & & & 1 & \\
\hline B2 & & & 1 & 2 & 2 & 1 & 1 & 2 & -1 \\
\hline B3 & & & & 1 & & & & 1 & \\
\hline B4 & & & & & 2 & 2 & 2 & -2 & -2 \\
\hline B5 & & & & & & 2 & & -1 & -2 \\
\hline B6 & & & & & & & & -1 & -1 \\
\hline B7 & & & & & & & & 2 & 2 \\
\hline B8 & & & & & & & & & 2 \\
\hline B9 & & & & & & & & & \\
\hline Position & A & A & A & D & D & N & N & A & A \\
\hline
\end{tabular}

Table 3. The matrix of communications in the project $\mathrm{C}$.

\begin{tabular}{|c|c|c|c|c|c|c|c|}
\hline Participant & C1 & C2 & C3 & C4 & C5 & C6 & C7 \\
\hline C1 & & 2 & 2 & -2 & 1 & -1 & 2 \\
\hline C2 & & & 1 & & & 1 & \\
\hline C3 & & & & -1 & 1 & 1 & \\
\hline C4 & & & & & 2 & -1 & \\
\hline C5 & & & & & & & \\
\hline C6 & & & & & & & \\
\hline C7 & & & & & & & \\
\hline Position & A & A & A & D & D & N & N \\
\hline
\end{tabular}

\subsection{Analysis of result}

The data about the structure of project communications were investigated using the freeware Pajek [23], presented by its authors to open access.

Visualization models of networks' structure are illustrated by graphs whose vertices correspond to the project participants and edges reflects meaningful communication between them. Since initially it was assumed that existed communications were mutual directed, undirected graphs was used for building the models. The models of communication networks for the investigated projects are shown in the figures $1,3,5$. The communications with positive character are shown by solid line and with positive character - by dashed. The participants' positions in the conflicts are illustrated by color of its vertices: white color is corresponding "Agree", black - "Disagree", gray - "Neutral".
The rule of finding a balanced solution for a particular network can be formulated as follows: the balanced solution should contain that partition of the network into subgroups (clusters) in which all positive ties are within clusters and negative are located between them. It should be given that the formulated rule describes an ideal situation, in which positive and negative ties between network members are placed respectively strictly inside the clusters or outside. It do not occurs always in real life, so researchers using the error weight factor $\alpha$ can control the program threshold for penalizing of erroneous negative ties within subgroups (valid values range from 0 to 1). The error weight factor for erroneous positive ties between subgroups counts automatically as $(1-\alpha)$. For the present study it is used $\alpha=0,5$. This factor can be explained from a socio-psychological point of view. Before selecting a value of $\alpha$ researcher should assess participants' tolerance to those with whom they have a negative attitude. If, in the opinion of the researcher, 
project members exist in an atmosphere of strong rejection of the opposite point of view, $\alpha$ should be defined close to 1 . On the contrary, in the case where

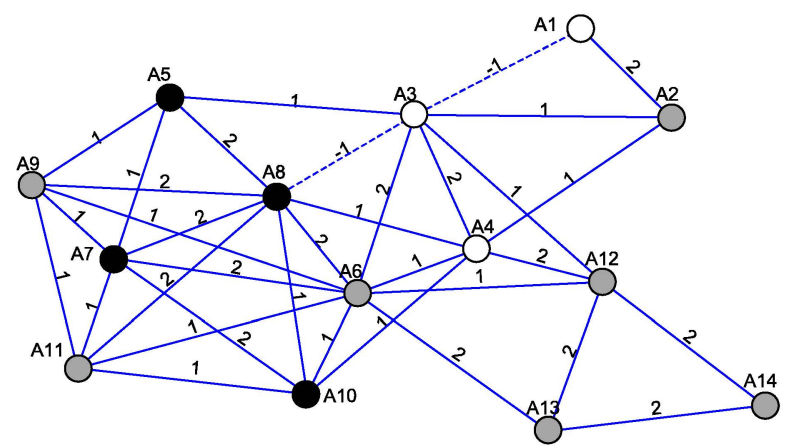

Figure 1. The communication network in the project A.

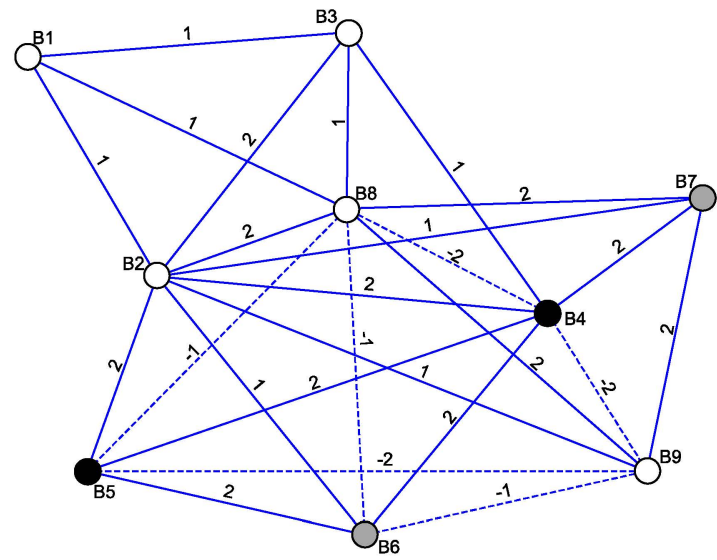

Figure 3. The communication network in the project B.

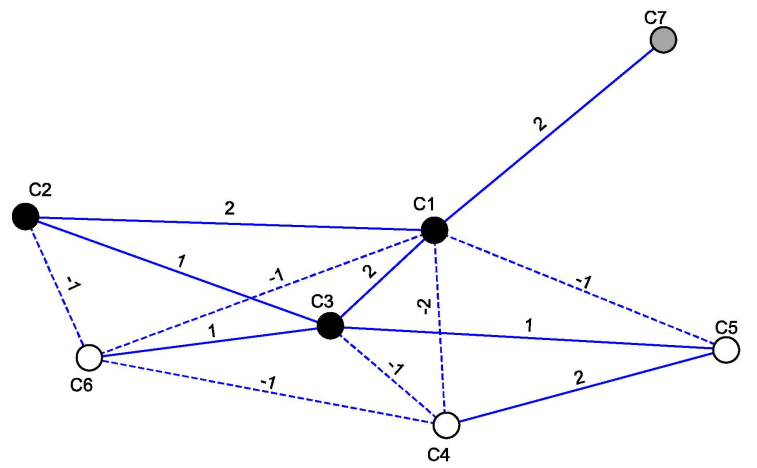

Figure 5. The communication network in the project C.

Found balanced solutions are presented in the Figures $2,4,6$. In this case used color coding are corresponding its membership of a new subgroup and not to the initial participant's position in the conflict. For example, in the project $\mathrm{A}$ the participant A3 initially demonstrated position «Agree» (its vertex in the figure 1 is white), but in the balanced network he joined the main subgroups (the black vertices in the figure 2). In the figure 3 the participant B1 was also marked with «Agree» position, but this project $\mathrm{B}$ member is the only participant in the grey-colored subgroup separated from the rest.

Comparing the found solutions with factual information about the projects it can be come to the following conclusions. In the project A there were 7 members in the open contradiction that is half of the total someone's disagreement does not prevent to consider him part of the team, $\alpha$ can be lowered closer to 0 .

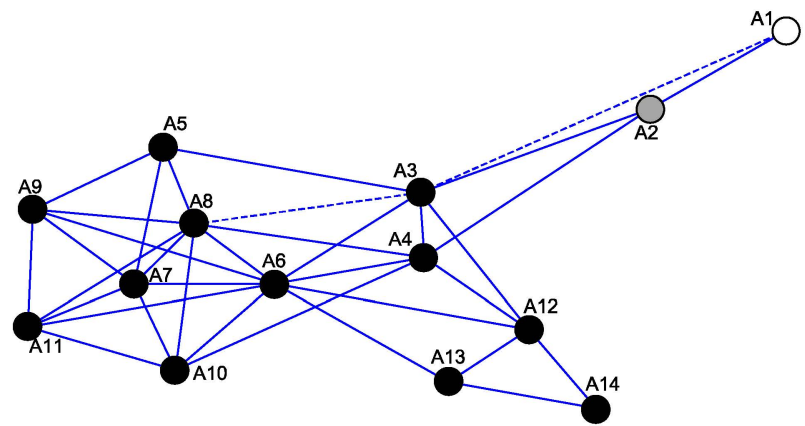

Figure 2. The balanced clustering in the project A network.

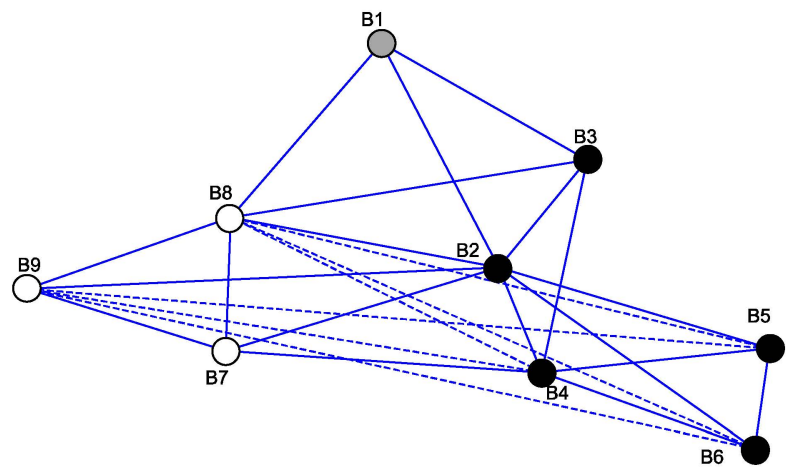

Figure 4. The balanced clustering in the project B network.

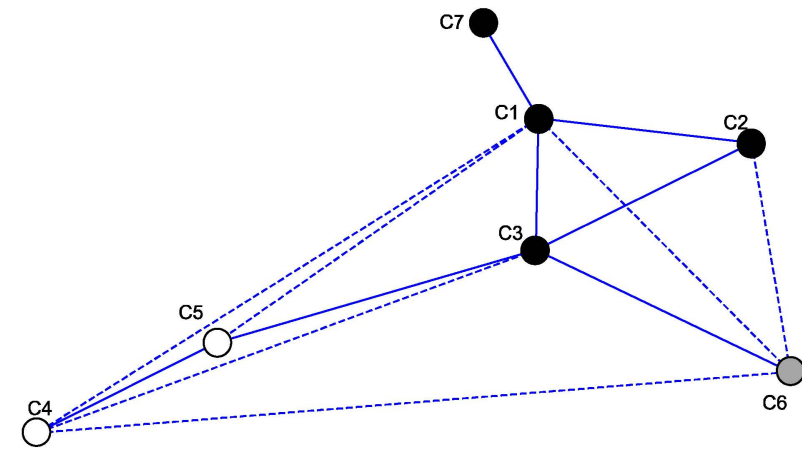

Figure 6. The balanced clustering in the project $\mathrm{C}$ network.

number of participants. The rest showed neutrality. It should be noted that the project A network contain only two negative ties in the communication structure. The balance analysis revealed that the 12 members belonged to the common subgroup. This fact shows about high emotional and psychological stability and cohesion of the project team, which is not influenced by differences of opinion, and therefore, about the high efficiency of communications management. Apparently, it was a significant factor contributing to overcoming conflict stage.

Comparing with project $\mathrm{A}$, there is a big share of negative relations in the communication structure of the project $B$. It can be assumed that in the situation with project $\mathrm{B}$ the conflict this project proceeded in a more 
critical stage adversely affecting the people relations. It is noteworthy that participants with the "Agree" position more than their opponents (5 vs. 2). But the figure 4 with balanced network is showing the presence of 2 subgroups, almost the same number of participants. The nature of the relations between the parties became a potential cause of a more radical separation, and therefore it reduced the level of mutual cooperation. So the negative attitude in the communications of participants B6 with B8 and B9 contributes to transition B6 from the neutral position to the opposition to them. For the participants B2 and B3 who shared the "Agree" position the results are more interesting because next these persons joined to subgroup with one's opponents B4 and B5. Such situation when a network member has better relations with opponents than with supporters is reinforcing the dissociation. Divergent views, the lack of sympathy in relationships with peers have a negative impact on decision making. The participants of the project B pointed to the lack of coherence in the goals understanding. The analysis of the balanced network showed that the participants, among whom there was the nominal consent could turn out to be opponents.

The project $\mathrm{C}$ network divided clearly into 3 subgroups, between which negative attitudes are dominated. It can be noted that the participants $\mathrm{C} 4$ and C6 have only one positive link with the other that is blocking effective cooperation. Observing the pattern of the balanced network in the project $\mathrm{C}$, the withdrawal of the several team members from the project seems to be in a predictable step. Communications and relationships between the participants are not contributing to the conflict resolution, and therefore, in this case it is hardly to expect achieving the project goals.

In the project $\mathrm{A}$ the communication network was stable when a conflict occurred. Its members had opposing points of view but could maintain positive attitudes with their opponents. Consequently, the team remained cohesive and kept the common goals and vision. In contrast, separate subgroups, in opposition to each other were clearly distinguished. Prevailing negative relationships between subgroups hindered information exchange and reduced the overall productivity of the teams. The lack of situation analysis in which the projects $\mathrm{B}$ and $\mathrm{C}$ were and insufficient efforts in relation to communication management became possible causes of disunity and the project failures.

\section{Conclusions}

Interproject communications are the integration environment for the participants, transforming them from individual actors into a united team. Using modern approaches in the organization theory, project teams can be classified as specific social networks. Formal and informal communications taken together constitute the project communication environment. Relations characters and their structure depend on project management effectiveness, and, therefore, can serve as indicators of project success.
Using the social network concept as a basis, the authors present the study communication characters and structure in the several projects that were in a conflict state. SNA techniques were chosen in order to examine structural balance of the project network. The analysis results gave opportunities to advance explanations regarding outcomes for each project taking into account social ties and member partitioning in the conflicts.

The use of SNA methods seems promising as a tool for analyzing of communication management effectiveness in addition to traditional methods for assessing quality of project management. This would pay more attention on human and social factors because project participants are essential element which deliver project results.

\section{References}

1. J.R. Turner and R. Müller, Int J Project Manage, 21, 1 (2003)

2. T. Cooke-Davies, Int J Proj Manage, 20, 185 (2002)

3. M.B. Pinto and J.K. Pinto, JPIM, 7, 200 (1990)

4. P.S. Chinowsky, J. Diekmann and J. O'Brien, JCEM, 136, 452 (2009)

5. P. Dietrich, IJPM, 37, 49 (2006)

6. H. Kerzner, Advanced project management: Best practices on implementation (2004)

7. H.J. Thamhaim and D. L. Wilemon, SLOAN MANAGE REV., 16, 31 (1975)

8. W.A. Reed, Doctoral dissertation (2006)

9. D. Hinds and R. M. Lee, Hawaii International Conference on System Sciences, Proceedings of the 41st Annual, IEEE, pp. 323-323 (2008)

10. P. He, B. Li and Y. Huang, Second International Conference on CGC, pp. 418-423 (2012)

11. R. Alsamadani, M. Hallowell and A. N. JavernickWill, CEM, 31, 568 (2013)

12. T. Mueller-Prothmann and I. Finke, J. UCS, 10, 691 (2004)

13. S.D. Pryke, Construct Manag Econ, 23, 927 (2005)

14. A. El-Sheikh and S.D. Pryke, Construct Manag Econ, 28, 1205 (2010)

15. P. Chinowsky, J. Diekmann and V. Galotti, JCEM, 134, 804 (2008)

16. P. Chinowsky and J.E. Taylor, EPOJ, 2, 15 (2012)

17. H.R. Kerzner, Project management: a systems approach to planning, scheduling, and controlling (2013)

18. S. A. Titov, Cloud of science, 1, 665 (2014)

19. I.V. Osipov, A.A. Volinsky and V.V. Grishin, International Journal of advanced computer science and applications, 6, 11 (2015)

20. I.V. Osipov, E. Nikulchev, A.A. Volinsky and A.Y. Prasikova, International Journal of advanced computer science and applications, 6, 71 (2015)

21. S. Wasserman and K. Faust, Social Network Analysis: Methods and Applications (1994)

22. W. De Nooy, A. Mrvar and V. Batagelj, Exploratory social network analysis with Pajek, 27 (2011) 